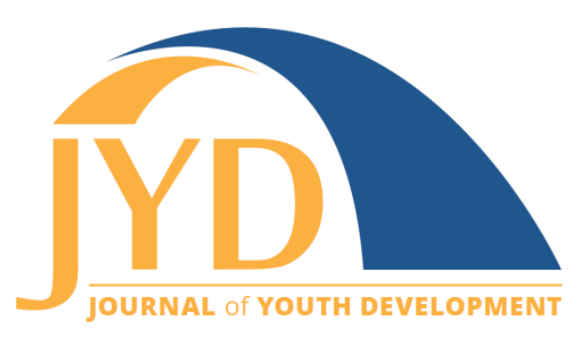

http://jyd. pitt. edu/ | Vol. 13 Issue 3 DOI 10.5195/jyd.2018.602 | ISSN 2325-4017 (online)

\title{
Building Healthy Communities: Creating Policy to Sustain Health-Related School Change
}

\author{
Erin Elizabeth Centeio \\ University of Hawaii at Manoa \\ ecenteio@hawaii.edu \\ Jeanne M. Barcelona \\ Wayne State University \\ gm8864@wayne.edu \\ Kristen Kaszeta \\ Wayne State University \\ Kristen.kaszeta@wayne.edu \\ Nate McCaughtry \\ Wayne State University \\ natemccaughtry@wayne.edu
}

\begin{abstract}
Many organizations including the Centers for Disease Control and Prevention and the National Academies of Science have called on schools to address childhood obesity and provide more opportunities for children to be active and eat healthier. This study discusses the impact that one comprehensive school program, Building Healthy Communities (BHC), had on school policy across 40 Midwest elementary schools. The study aim was to assess elementary schools that participated in the BHC whole-of-school intervention and examine the policy changes that took place during the year-long intervention, as well as proposed changes made as part of a sustainability plan. Findings indicated that evidenced-based tools can spur awareness of the need for health-based school change among administration, which in turn can prompt the adoption of school-level adherence policies. The intersection between school-based health policy and community-based youth programs is explored as an important part of comprehensive youth health promotion.
\end{abstract}

Key words: school policy; whole school, whole community, whole child; physical activity; healthy eating; comprehensive school physical activity programs

(c) $\mathbf{E Y}$ New articles in this journal are licensed under a Creative Commons Attribution 4.0 License. This journal is published by the University Library System, University of Pittsburgh and is cosponsored by the University of Pittsburgh Press. The Journal of Youth Development is the official peer-reviewed publication of the National Association of Extension 4-H Agents and the National AfterSchool Association. 


\section{Introduction}

In the United States and around the world, it is well known that youth have high rates of overweight and obesity and this can lead to health issues later in life (Ogden, Carol, Kit, \& Flegal, 2014). Currently over one-third of America's youth are overweight or obese and this leads to higher incidences of co-morbidities including, high blood pressure, diabetes, and mental health issues, both when they are young and leading into their adult lives (Pulgarón, 2013). Improved healthy habits, such as increased physical activity and healthy eating behaviors, can impact weight status and stave off chronic disease later in life (Singh, Mulder, Twisk, Van Mechelen, \& Chinapaw, 2008). The physical activity guidelines for youth encourage children to be active at least 60 minutes a day (U.S. Department of Health and Human Services, 2008). Unfortunately, achieving this recommendation is difficult, given that children spend most of their waking hours in school, a traditionally sedentary setting (Bartholomew \& Jowers, 2011). Many organizations have suggested that schools should increase the amount of opportunities for children to be active (Institute of Medicine of the National Academies [IOM], 2013; Centers for Disease Control and Prevention [CDC], 2013). However, a new conceptualization of this strategy calls for schools to engage in community partnerships as a means to create more opportunities for children to be active before, during, and after school (Gamble, Chatfield, Cormack, \& Hallam, 2017).

The National Academy of Medicine and the CDC have called on schools to create a culture of health where youth have opportunities to engage in physical activity and have access to healthy foods options (CDC, 2013; IOM, 2013). Although many governmental and private organizations at the national level encourage healthy cultures in schools, adopting this culture into schools has been a challenge for various reasons. Recognizing that several factors have the capacity to influence such changes in schools, the CDC in accordance with the Association for Supervision and Curriculum Development (ASCD) developed the Whole School, Whole Community, Whole Child (WSCC) framework (Lewallen, Hunt, Potts-Datema, Zaza, \& Giles, 2015) to guide the examination of such relationships. The WSCC model, which takes a social ecological approach, highlights the dynamic relationship between intrapersonal, interpersonal, and community levels. WSCC emphasizes the impact of access to quality health and physical education, nutrition, health-based services, and a positive social and emotional climate, as well as the engagement of faculty and community. Implementing, adopting, and sustaining these health-related factors into schools and across the school day is not easy (Naylor et al., 2015). In fact, local-level policies have become the accountability measures necessary to drive health-related work in schools (Dietz \& Gortmaker, 2016). 
Policy has been identified as the driving force for health-related change in schools (Lott, Schwartz, Story, \& Brownell, 2018; Webster, Russ, Vazou, Goh, \& Erwin, 2015). The implementation of school nutrition policies has enhanced the school nutrition environment by significantly diminishing youth access to sugar-sweetened beverages and low nutrient-dense food (Boles et al., 2011; Kubik, Farbakhsh, \& Lytle, 2011). Policies have also strengthened health-based programming by increasing physical education time and children's participation in physical activity (Kelder et al., 2009; Slater, Nicholson, Chriqui, Turner, \& Chaloupka, 2012). The classroom environment has also been transformed through policies leading to healthy classroom parties (Belansky et al., 2010), routine physical activity (Story, Nanney, \& Schwartz, 2009) and social-emotional learning (Jones \& Bouffard, 2012). Such policies lay a foundation for developing a healthy school community.

School policy adoption and adherence is driven by the use of evidenced-based resources and tools. For example, the School Health Index (SHI) was developed at the national level through the CDC to allow individual districts and schools to monitor youth health and safety (CDC, 2017). The SHI, an evidenced-based tool, has been readily received across the nation. The SHI helps guide schools through a self-assessment process to understand better how their school is meeting guidelines set forth by the CDC and through the WSCC model. Recently, more statespecific tools, meant to support localized policy needs, have also emerged. In Michigan, the Department of Education and Michigan Department of Health and Human Services collaborated to develop the Healthy School Action Tool (HSAT), a two-fold resource that is based on the SHI. The HSAT was developed to allow districts and schools to self-assess their health environment in order to develop an appropriate action plan (Michigan Department of Health and Human Services, 2014). The HSAT maps onto the WSCC framework, assessing the health environment across seven domains (healthy eating, physical education and physical activity, health education, staff wellness, social and emotional health, safety, and tobacco free). The assessment feedback gained from the HSAT or SHI provides strengths and weaknesses of the school based on the components of the WSCC model and spurs development of a comprehensive action plan that aligns with the specific needs of individual districts and schools. This dynamic relationship between the model and the outcomes of the assessment tools have the potential to stimulate meaningful, health-based, environmental change. 


\section{Building Healthy Communities}

\section{The Building Healthy Communities Program}

There are some schools across the United States that are convinced whole-of-school approaches are important and can benefit both the overall health and academic achievement of youth. An example of a program that is heavily funded in part of the Midwest is the Building Healthy Communities (BHC) program. The BHC program is a social-ecological based, comprehensive schoolwide intervention that emphasizes the adoption of a healthy school culture where children are provided access, knowledge, and support to make healthy eating choices as well as to integrate physical activity across the school day (Centeio et al., 2018a). Given the need for healthy school cultures, BHC has been successfully replicated in more than 140 Midwest elementary schools since 2012. Student-level outcomes of the BHC program adoption include increased physical activity (Centeio et al., 2014), exposure to a variety of new healthful foods and increased fruit, vegetable, and dairy consumption aligning with national standards. Students have significantly increased their amount of moderate to vigorous physical activity time and reduced their BMI and central adiposity (Centeio et al., 2014; Centeio et al., 2018b). These changes enable children to lower their risk for chronic disease later in life. Given the compelling evidence that BHC positively impacts the health and well-being of school-age children, educators voiced a need to advocate for health and wellness policies to encourage adherence and surveillance of vital program components.

Understanding how schools undergo a culture change surrounding health within a school setting is important. However, identifying what actually changes within and around the school setting to embrace a culture of health is even more important, as it will help other schools be successful in making their own changes. Furthermore, investigating how school policy focusing on physical activity and healthy eating environments changes during interventions is essential when thinking about sustainability for the future. Therefore, this exploratory study assessed schools that participated in the BHC whole-of-school intervention, and it examined the policy changes that took place during the year-long intervention as well as proposed changes that were planned to take place as part of a sustainability plan. Further, this paper discusses how these changes inform the need for school- and community-level collaborations in order to help support opportunities to improve the health of youth.

\section{Method}

The BHC program is composed of six key components: (a) principal engagement, (b) quality physical education, (c) classroom education regarding healthy eating and physical activity, (d) 


\section{Building Healthy Communities}

active recess, (e) student leadership team, and (f) healthy kids club (an afterschool physical activity program). Detailed information about the program components have been previously published (Centeio et al., 2018a). The schools in this study took part in the BHC program for a period of one year, in collaboration with grant staff who help facilitate capacity around the six components. In February of the 2016-2017 school year, schools completed the HSAT assessment. Through the HSAT assessment process, a school-specific action plan was automatically generated based on each school's weaknesses. Although it is not a requirement of the program, BHC grant staff (i.e., school coordinators) encouraged schools (and their principals) to take the given action plan and work toward positive changes in policy in order to help sustain a culture of health and align with the WSCC model.

Over the course of one school year (2016-2017), 40 schools participated in the BHC program. During the year, survey data were collected to investigate the degree to which local-level policy changed in order to help sustain a culture of health within the school both during the school year and beyond. A total of 38 principals and 144 classroom teachers participated in this study. Schools were located across the state of Michigan in urban, suburban, and rural areas. School enrollments ranged from 116 to 675 students. Demographic information on teachers and principals was not collected.

\section{Data Analysis}

This mixed methods study gathered information through closed- and open-ended questions. Some of the questions focused on policy changes that took place during implementation of the $\mathrm{BHC}$ program and other questions focused on future policies that teachers and principals planned to enact the following school year. An example of a question asked of principals was "How likely are you to implement any items from your HSAT action plan in the future?" Principals were given choices based on a 5-point Likert scale ranging from 1 ("not at all likely") to 5 ("extremely likely"). Additionally, principals were asked follow-up questions that were open ended. For example, "If you do plan on implementing any items from your HSAT action plan in the future, what do foresee yourself trying to change/implement?" Frequencies of policy-related questions were run to identify awareness and intention of policy changes within the schools. Results from the quantitative findings informed the qualitative data analysis, which was used to provide a deeper understanding of each school's intentions to move forward and support triangulation of data (Creswell, 1998). Qualitative data were coded (Willis, 2007) and reported out in relation to the WSCC Model. Specifically, each answer that was collected was categorized within the WSCC model to reflect student-level, school-level, or community-level changes. 


\section{Results}

After engaging in the BHC program for an entire school year, principals were asked if they planned on continuing any part of the program in the upcoming years. Almost all of the principals (97\%) indicated they wanted to continue most, if not all, BHC program components. A total of $73 \%$ reported that they would continue the student leadership team and $71 \%$ wanted to continue the after-school physical activity clubs and classroom physical activity breaks, while $65 \%$ stated they would continue the principal engagement component. The principals felt that they were least confident in keeping the eight healthy eating lessons that took place in the elementary classrooms each month.

As aforementioned, in February of 2017, schools were asked to have a team of people complete the HSAT. Teams included principals, classroom teachers, PE teachers, and other school leaders. As part of the HSAT assessment, schools were presented with a school-specific action plan of items that they could improve in their school environment.

Based on what they reported for their HSAT assessment, principals were asked if they had intentions of implementing any of the action items that were presented though the HSAT action plan and $71 \%$ reported that they would be implementing one or more of the HSAT action items. When asked the type of action items that they would move forward on, $75 \%$ of principals reported action items related to the school environment, while $12.5 \%$ respectively reported focusing on student or community changes. For example, principals (41\%) most often reported intentions to change the physical education and physical activity environments with plans such as "to continue a before- and after-school program," "training lunch teachers to provide additional physical activity experiences for the students," and "increasing physical activity opportunities through after-school club, Girls on the Run, and classroom brain breaks."

It is important to note that principals were not just focusing on changing issues surrounding physical activity and healthy eating, as $12 \%$ of principals reported intended changes to employee wellness and the social-emotional climate of the school. For example, principals wrote action items as such: "more physical involvement from staff," "focusing more on social, emotional health and the whole child," and similarly, "we are incorporating social emotional health into our school improvement plan next year." 


\section{Building Healthy Communities}

When asked about school policies that changed over the period of BHC grant implementation, classroom teachers reported that many had already made changes to policy within their classroom environments throughout BHC implementation. They reported three types of changes: physical activity (41\%), nutrition (26\%), and employee wellness (3\%). Specifically, classroom- level policy changes included increasing physical activity breaks throughout the day, not removing recess as punishment, and classroom healthy party and snack policies.

Given the teachers' role in implementing changes in the school environment, classroom teachers were also asked if they had plans to implement part of the HSAT action plan the following school year. Forty-five percent of teachers reported that they planned to implement at least one portion of the action plan. Of the 17 intended changes, 16 of the action items were school environment related and one was community focused. In fact, $35 \%$ of the action items reported focused on changes to the physical education and physical activity environments, while $23 \%$ focused on nutritional changes. For example, one teacher stated, "I want to increase physical activity in the classroom. Our scores seemed lower than we anticipated and I am looking for ways to improve them." Another stated, "I am going to use the Michigan Model more in the classroom to help my students learn about nutrition and general health."

\section{Discussion}

This study investigated the role of policy as it relates to meaningful and sustainable programming centered on the WSCC model. Broadly, findings indicated that evidenced-based tools can spur awareness of the need for health-based school change among administration, which in turn prompts the adoption of school-level adherence policies. These results are promising as they indicate that with proper knowledge and support, change is possible, but they also shed light on the need to consider community entities and their partnerships within and beyond the school setting.

\section{The Sustainable Footprint of Health-Based School Culture Change}

Programs such as BHC encourage educational leaderships' implementation of the HSAT action plan, which has the capacity to guide schoolwide policy implementation. Essentially, school policy is a dynamic relationship orchestrated by the school administration within a given building. Accordingly, this educational leadership must commit to an alliance where consideration of the child and the child's successful development is placed at the center of all policy-driven change. 
Broadly, results indicated that in February of 2017, after just over one-half year of programming, administrators were willing to take on the task of assessing their school's need for health-based changes across the individual, school, and community environment. School administration used the HSAT to assess and guide planning for future policy implementation and environmental change. Results indicated that as administrators completed the HSAT and received their individualized action plan, they intended to implement further change in their schools by targeting the domains of healthy eating, physical education and physical activity, and social-emotional climate.

Upon completion of the granting period for BHC programming, teachers were surveyed to determine environmental changes that occurred in the school setting. Most teachers reported policy change, specifically indicating that they had developed classroom policies to promote a healthy culture. Teachers indicated that their classroom policies were centered on increasing physical activity (e.g., movement breaks) and the adoption of nutrition standards (e.g., healthy celebrations).

The results also showed the development of change over time. Specifically, the results reported by administrators at midyear showed intent to make environmental changes, but at the end of the year teachers reported policy changes within the classroom. This suggests that tools such as the HSAT prompt administration to contemplate and guide health-based change in their school. Programs such as BHC have the potential to educate administration on the importance of using evidenced-based tools such as SHI and HSAT to identify areas of weakness and support. This can allow administrators and teachers to use the outcomes from such assessments to strategically implement health-based school change. Without this level of commitment from quality programming, these changes may not be sustainable.

The HSAT results also indicated that administration voiced intent to continue specific components of the BHC program beyond its funding period. Specifically, they identified afterschool physical activity programming, classroom physical activity breaks, and student leadership teams as BHC program components they would like to sustain. This shows promise that when administrators are educated on the importance of a healthy school culture and are supported through the initial phases of health-based changes in their schools, sustainable changes are feasible. 


\section{Leveraging the Outcomes of Health-Based Change in School to Recruit Community Partnerships}

The public health sector has a long-standing record of promoting the school setting as an optimal point of intervention for youth health (CDC, 2013; IOM, 2013). There have been several successful school-based interventions including Child and Adolescent Trial for Cardiovascular Health (CATCH; Luepker et al., 1996) and Physical Activity Across the Curriculum (PAAC; Donnelly \& Lambourne, 2011), as well as BHC boasting both physical and mental health benefits for children. However, as the WSCC model illustrates, it is not effective to create programming silos and isolate schools as the only hope for intervening on youth health. Youth, are a part of their school community, and they also interact and embody a community beyond their school walls. Accordingly, it is imperative that schools and researchers begin to consider the value in community partnerships. Schools and community partners should be working together to ensure that students are able to participate in at least 60 minutes of daily physical activity both during the school week and on the weekends. Furthermore, working together to ensure consistent and relevant programming is essential. There are limited instances where school and community partnerships have established a cohesive front to meet the needs of the whole child. As partnerships develop it is important to remember, as evidenced by socialecological models such as the WSCC, that in order for community-level partnerships to have impact, programming must develop the child's physical, social, and environmental capital (Valli, Stefanski, \& Jacobson, 2016).

\section{Physical Capital}

After-school and enrichment programs should be encouraged to join the alliance of schoolbased educators committed to implementing health-based policy and program-based changes (CDC, 2013). Without continual reinforcement across sectors a promise of the lifelong adoption of a healthy lifestyle is diminished. When after-school and enrichment programs also prioritize access to routine physical activity engagement and healthy eating beyond the school day, the child's potential to adopt a lifelong healthy lifestyle is further supported (Weaver, Beets, Saunders, Beighle, \& Webster, 2014). Therefore, future interventions would benefit from forming partnerships between schools and their after-school enrichment providers centered around health-based policy consistency before, during, and after the school day. Such partnerships may also consider providing additional professional development to educate afterschool providers about the importance of youth health. Expanding our consideration for health programming beyond the school to the surrounding community environment creates a strong and dynamic relationship that is much needed. 


\section{Social Capital}

In addition to the support that after-school enrichment programs can provide, there is a great need for community programming that supports familial engagement (Grant \& Ray, 2018). Research indicates a relationship between familial programming and children's physical activity (Hearst, Wang, Grannon, Davey, \& Nanney, 2017) and nutrition (Story, Neumark-Sztainer, \& French, 2002). However, developing the bridge between school and home proves to be quite challenging (Langford, Bonell, Jones, \& Campbell, 2015). Accordingly, communities would benefit from providing meaningful and culturally-relevant programming in which families feel comfortable and compelled to engage. For example, Arab American families may be more responsive to community-center programming as it seeks to build community through embracing and honoring culturally-specific physical activity and healthy eating rituals (Otero Bracco \& Eisenberg, 2017). Research also evidences the significant capacity for church spaces to support and engage African American families positively (Boyd, 2018). Successful nutrition and physical activity programming among Latino families has been provided by community entities and housed within school settings as after-school supplemental learning (Besnilian, Johnson, \& Plunkett, 2018). Finally, disparate urban and culturally diverse communities such as those found in the city of Detroit have also stepped up to provide successful interventions for families and children through the provision of health-based programming provided in local Detroit-based homes. Through such family-based approaches, children are supported in their pursuit of health and happiness (Coombe et al., 2017). Community partnerships have the capacity to encourage, support, and advance a family's health and in doing so provide the foundation for lifelong healthy habits among youth.

\section{Environmental Capital}

The environment has been evidenced as a primary correlate of health across the lifespan (Piccolo, Duncan, Pearce, \& McKinlay, 2015). Specifically, access to local and fresh grocery stores (Cavanaugh et al., 2014), open spaces and parks (Wolch, Byrne, \& Newell, 2014) and capacities to advance health literacy (Batterham, Hawkins, Collins, Buchbinder, \& Osborne, 2016) have proven successful in enhancing the health and well-being of communities at large. Accordingly, communities hold a responsibility for ensuring equitable access for children and families to healthy foods and spaces. Community partnerships committed to fostering and sustaining healthy youth development not only ensure the livelihood of their own neighborhood, they advance the potential for the greater population. 


\section{Conclusion}

The consideration for future directions of community-level partnerships is exciting because it is feasible and holds potential to make a significant impact on society. However, it is important to remember that transformation takes time, knowledge, and resources. It begins in the school with a self-assessment that prompts policy change and programming implementation. The school can identify areas of need and reach out to community partners to help fill gaps that the school, logistically, cannot fill. There is no quick fix when looking to modify the environment; it is multi-level and systematic (Webster, Beets, Weaver, Vazou, \& Russ, 2015). However, it is possible, and the assurance that every child can succeed and improve their overall health and well-being is worth the effort.

\section{Acknowledgements}

We would like to thank Blue Cross Blue Shield of Michigan, Michigan Department of Health and Human Services, United Dairy Industry of Michigan, Food Corps, and Gopher Sports for their generous funding and support.

\section{References}

Batterham, R. W., Hawkins, M., Collins, P. A., Buchbinder, R., \& Osborne, R. H. (2016). Health literacy: Applying current concepts to improve health services and reduce health inequalities. Public Health, 132, 3-12.

Bartholomew, J. B., \& Jowers, E. M. (2011). Physically active academic lessons in elementary children. Preventive Medicine, 52(1), S51-S54.

Belansky, E. S., Cutforth, N., Delong, E., Litt, J., Gilbert, L., Scarbro, S., \& Marshall, J. A. (2010). Early effects of the federally mandated local wellness policy on school nutrition environments appear modest in Colorado's rural, low-income elementary schools. Journal of the American Dietetic Association, 110(11), 1712-1717.

Besnilian, A., Johnson, P., \& Plunkett, S. W. (2018). A taste of good health: Evaluation of a school-based, healthy lifestyles program for parents in Latino communities. Family and Consumer Sciences Research Journal, 46(3), 205-218.

Boles, M., Dilley, J. A., Dent, C., Elman, M. R., Duncan, S. C., \& Johnson, D. B. (2011). Changes in local school policies and practices in Washington state after an unfunded physical activity and nutrition mandate. Preventing Chronic Disease, 8(6), A129. 


\section{Building Healthy Communities}

Boyd, L. N. (2018). Fortifying parent partnerships through the black church space. In K. E. L. Norris \& S. Collier (Eds.), Social justice and parent partnerships in multicultural education contexts (pp. 118137). Hershey, PA: IGI Global.

Centeio, E. E., McCaughtry, N., Gutuskey, L., Garn, A., Somers, C., Shen, B., Martin, J., \& Kulik, N. (2014). Physical activity change through comprehensive school physical activity programs in urban elementary schools. Journal of Teaching in Physical Education, 33, 573-591. doi: 10.1123/jtpe.2014-0067

Centeio, E. E., Somers, C. L., Moore, E. W. G., Kulik, N., Garn, A., Martin, J., \& McCaughtry, N. (2018a). Relationship between academic achievement and healthy school transformations in urban elementary schools in the United States. Physical Education and Sport Pedagogy, 23(4), 402-417. doi: 10.1080/17408989.2018.1441395

Centeio, E. E., McCaughtry, N., Moore, E. W. G., Kulik, N., Garn, A., Martin, J., ... Fahlman, M. (2018b). Building healthy communities: A comprehensive school health program to prevent obesity in elementary schools. Preventive Medicine, 111, 210-215.

Cavanaugh, E., Green, S., Mallya, G., Tierney, A., Brensinger, C., \& Glanz, K. (2014). Changes in food and beverage environments after an urban corner store intervention. Preventive Medicine, 65, 712.

Centers for Disease Control and Prevention [CDC]. (2013). Make a difference at your school. Retrieved from https://www.cdc.gov/healthyyouth/keystrategies/pdf/make-a-difference.pdf

Centers for Disease Control and Prevention [CDC]. (2017). School Health Index. Retrieved from https://www.cdc.gov/healthyschools/shi/

Coombe, C. M., Reyes, A. G., Grant, S., Schulz, A. J., Israel, B. A., Clement, J., . . \& \& Smith, S. (2017). Strengthening community capacity in Detroit to influence policy change for health equity. Michigan Journal of Community Service Learning, 23(2), 101-117.

Creswell, J. W. (1998). Qualitative inquiry and research design: Choosing among five traditions. Thousand Oaks, CA: Sage.

Dietz, W. H., \& Gortmaker, S. L. (2016). New strategies to prioritize nutrition, physical activity, and obesity interventions. American Journal of Preventive Medicine, 51(5), e145-e150.

Donnelly, J. \& Lambourne, K. (2011). Classroom based physical activity, cognition, and academic achievement. Preventive Medicine, 52, S36-S42.

Gamble, A., Chatfield, S. L., Cormack, M. L., \& Hallam, J. S. (2017). Not enough time in the day: A qualitative assessment of in-school physical activity policy as viewed by administrators, teachers, and students. Journal of School Health, 871), 21-28.

Grant, K. B., \& Ray, J. A. (Eds.). (2018). Home, school, and community collaboration: Culturally responsive family engagement. Los Angeles, CA: Sage Publications. 


\section{Building Healthy Communities}

Jones, S. M., \& Bouffard, S. M. (2012). Social and emotional learning in schools: From programs to strategies. Society for Research in Child Development, 26(4), 3-22.

Hearst, M. O., Wang, Q., Grannon, K., Davey, C. S., \& Nanney, M. S. (2017). It takes a village: Promoting parent and family education on healthy lifestyles for Minnesota secondary students. Journal of School Health, 8ス1), 55-61.

Institute of Medicine of the National Academies. (2013). Educating the student body: Taking physical activity and physical education to school. Washington, DC: The National Academies Press. Retrieved from http://www.nationalacademies.org/hmd/Reports/2013/Educating-the-StudentBody-Taking-Physical-Activity-and-Physical-Education-to-School.aspx

Kelder, S. H., Springer, A. S., Barroso, C. S., Smith, C. L., Sanchez, E., Ranjit, N., \& Hoelscher, D. M. (2009). Implementation of Texas Senate Bill 19 to increase physical activity in elementary schools. Journal of Public Health Policy, 30(1), S221 - S247.

Kubik, M. Y., Farbakhsh, K., \& Lytle, L. A. (2011). Two years later: Wellness councils and healthier vending in a cohort of middle and high schools. Journal of Adolescent Health, 49, 550-552.

Langford, R., Bonell, C., Jones, H., \& Campbell, R. (2015). Obesity prevention and the health promoting schools framework: Essential components and barriers to success. International Journal of Behavioral Nutrition and Physical Activity, 12(1), 15.

Lewallen, T. C., Hunt, H., Potts-Datema, W., Zaza, S., \& Giles, W. (2015). The whole school, whole community, whole child, model: A new approach for improving educational attainment and healthy development for students. Journal of School Health, 85(11), 729-739.

Lott, M., Schwartz, M., Story, M., \& Brownell, K. D. (2018). Why we need local, state, and national policybased approaches to improve children's nutrition in the United States. In M. S. Freemark (Ed.). Pediatric obesity: Etiology, pathogenesis and treatment ( $2^{\text {nd }}$ ed., pp. 731-755). Cham, Switzerland: Springer International Publishing.

Luepker, R. V., Perry, C. L., McKinlay, S. M., Nader, P. R., Parcel, G. S., Stone, E. J., . . \& Verter, J. (1996). Outcomes of a field trial to improve children's dietary patterns and physical activity. The Child and Adolescent Trial for Cardiovascular Health. CATCH collaborative group. JAMA, 275, 768-776.

Michigan Department of Health and Human Services. (2014). Healthy School Action Tool. Retrieved from http://mihealthtools.org/hsat/

Naylor, P. J., Nettlefold, L., Race, D., Hoy, C., Ashe, M. C., Higgins, J. W., \& McKay, H. A. (2015). Implementation of school based physical activity interventions: A systematic review. Preventive Medicine, 72, 95-115.

Ogden, C. L., Carroll, M. D., Kit, B. K., \& Flegal, K. M. (2014). Prevalence of childhood and adult obesity in the United States, 2011-2012. JAMA, 311(8), 806-814. 


\section{Building Healthy Communities}

Otero Bracco, C., \& Eisenberg, J. (2017). Neighbors Link's parent-child together program: Supporting immigrant parents' integration to promote school readiness among their emergent bilingual children. Journal of Multilingual Education Research, $\pi(1), 6$.

Piccolo, R. S., Duncan, D. T., Pearce, N., \& McKinlay, J. B. (2015). The role of neighborhood characteristics in racial/ethnic disparities in type 2 diabetes: Results from the Boston Area Community Health (BACH) Survey. Social Science \& Medicine, 130, 79-90.

Pulgarón, E. R. (2013). Childhood obesity: A review of increased risk for physical and psychological comorbidities. Clinical Therapeutics, 35(1), A18-A32.

Singh, A., Mulder, C., Twisk, J., Van Mechelen, W., \& Chinapaw, M. (2008). Tracking of childhood overweight into adulthood: A systematic review of the literature. Obesity Review, 9(5), 474-488.

Slater, S. J., Nicholson, L., Chriqui, J., Turner, L., \& Chaloupka, F. (2012). The impact of state laws and district policies on physical education and recess practices in a nationally representative sample of public elementary schools. Archives of Pediatric Adolescent Medicine, 166(4), 311- 316.

Story, M., Nanney, M. S., \& Schwartz, M. B. (2009). Schools and obesity prevention: Creating school environments and policies to promote healthy eating and physical activity. The Milbank Quarterly, 87(1), 71-100.

Story, M., Neumark-Sztainer, D., \& French, S. (2002). Individual and environmental influences on adolescent eating behaviors. Journal of the Academy of Nutrition and Dietetics, 102(3), S40-S51.

U.S. Department of Health and Human Services. (2008). 2008 Physical Activity Guidelines for Americans. Retrieved from http://www.health. gov/paguidelines/guidelines/summary.aspx

Valli, L., Stefanski, A., \& Jacobson, R. (2016). Typologizing school-community partnerships: A framework for analysis and action. Urban Education, 51(7), 719-747.

Weaver, R. G., Beets, M. W., Saunders, R. P., Beighle, A., \& Webster, C. (2014). A comprehensive professional development training's effect on afterschool program staff behaviors to promote healthy eating and physical activity. Journal of Public Health Management and Practice: JPHMP, 20(4), E6.

Webster, C. A., Beets, M., Weaver, R. G., Vazou, S., \& Russ, L. (2015). Rethinking recommendations for implementing comprehensive school physical activity programs: A partnership model. Quest, $67(2), 185-202$.

Webster, C. A., Russ, L., Vazou, S., Goh, T. L., \& Erwin, H. (2015). Integrating movement in academic classrooms: Understanding, applying and advancing the knowledge base. Obesity Reviews, 16(8), 691-701.

Willis, J. W. (2007). Foundations of qualitative research: Interpretive and critical approaches. Thousand Oaks, CA: Sage. 
Journal of Youth Development | http://jyd.pitt.edu/ | Vol. 13 Issue 3 DOI 10.5195/jyd.2018.602 Building Healthy Communities

Wolch, J. R., Byrne, J., \& Newell, J. P. (2014). Urban green space, public health, and environmental justice: The challenge of making cities 'just green enough'. Landscape and Urban Planning, 125, 234-244. 